\title{
Research on the Impact of the Work Motivation of Chinese Skilled Personnel on Work Engagement: An Analysis Based on the Perspective of Policy Identification
}

\author{
Jiawei $\mathrm{Yu}^{*}$ \\ Accounting and Management, Business school, University of Southampton,Southampton,SO17 1BJ,UK \\ *Corresponding Author's Email:withyu0723@outlook.com
}

\begin{abstract}
Skilled personnel are playing an increasingly important role in organizations. Considering that skilled personnel tend to be influenced by different types of motivations, and there is a certain relationship between their work motivation and work engagement. Based on this, the purpose of this paper is to research the relationship between work motivation of Chinese skilled personnel and work engagement from the perspective of policy identification. A quantitative analysis of the questionnaire method was adopted to address the research questions, and SPSS was used to analysis of the obtained data. Given the results have shown firstly work motivation of Chinese skilled personnel positively associates work engagement, and secondly policy identification and work engagement of Chinese skilled personnel are positively related. However, there was no indication that policy identification of Chinese skilled personnel plays a moderating role in the process of work motivation effects on work engagement. The contributions are mainly are twofold. Firstly, this paper contributes to the extending and linking of two separate literature (work motivation and work engagement, and policy identification). Secondly, focusing on Skilled personnel is innovative and can yield important insights into complex managerial problems.
\end{abstract}

Keywords: Work motivation, Work engagement, Policy identification, Chinese skilled personnel

\section{INTRODUCTION}

Skilled personnel is a segment of the workforce that has specialized know-how, training, and experience to carry out complex physical, or mental tasks on the front-line. While the number of skilled personnel is expected to steadily increase, the increased market competition and the ongoing transformations in technological, economic, and political environments still have existed structural problems of a shortage of skilled personnel. A large body of empirical research has proved that employees tend to be influenced by different types of motivations, and there is a certain relationship between their work motivation (WM) and work engagement (WE)[12,13,14]. Recently, the issue on '996' work schedule is highly debatable. Some would hold a positive attitude toward this issue by arguing that working overtime means more material rewards, while some others who are not concerned about material returns would insist that overtime is a waste of their personal time. In this context, different WM have an impact on the degree of WE. Based on the two aspects, this paper proposes to examine the impact of WM on WE of Chinese skilled personnel from the perspective of policy identification (PI).

Based on the above background and phenomena, the following research questions were developed: What is the relationship between WM and WE? What is the relationship between $\mathrm{WM}$ and PI? And what is the relationship between PI and WE?

This research aims to establish the relationships among three work characteristics constructs, namely WM, WE, and PI. To this end, this research will apply a quantitative analysis of the questionnaire method to address the research questions. Respondents were selected from China workplace and identified as skilled personnel according to the definition of this paper. This paper first briefly describes WM and WE of skilled personnel in China, as well as the PI of Chinese skilled 
personnel to the policy Guidelines on Salary Distribution of Skilled Personnel, and then conducts confirmatory analysis on the relationships among the three indicators, and finally draws the corresponding conclusions.

\section{LITERATURE REVIEW}

\subsection{Work motivation}

Pinder defined WM as intrinsic and extrinsic forces that stimulate behaviors in workplaces and determine the form, direction, intensity and duration of these behaviors[1]. The majority of existing studies divide motivation into intrinsic motivation (IM) and extrinsic motivation (EM) according to the different causes of motivation[2,3,4]. Different from EM that refers to incentives outside of work (e.g. salary, benefits), IM is regarded as personal psychological needs such as the satisfaction of work interest and autonomy, and the sense of competence[5]. Regarding the measurement of $\mathrm{WM}$, the one widely adopted by scholars is Work Preference Inventory (WPI) scale. The reliability of IM dimension of WPI scale is 0.75 , and that of EM dimension is $0.7[2]$, meaning the both IM and EM can be steadily evaluated.

\subsection{Work engagement}

Schaufeli defined WE as a positive, fulfilling, and durable state of emotion and cognition, with the dimensions of vigor, dedication, and absorption[6], and used the Job Demands-Resources Model (JD-R) to explain the mechanism of WE. JD-R model hypothesizes that job requirements are considered to be the main cause of burnout, while work resources are considered to be the main driving force of work[7].
Schaufeli developed the UWES scale, which has become the main measurement tool for scholars to conduct empirical research on WE. The empirical research that the internal consistency reliability of UWES three-dimensional degree is 0.73-0.77[8], which means that the scale has high reliability and validity. This research cites the simplified version that includes 9 items combined a 5-point Likert scale for scoring.

\subsection{The theory of policy identification}

Sang Yucheng pointed out that PI is the attitude of the approval, and support of the policy executors and relevant personnel in the implementation process of the policy[9]. In essence, PI is the psychologically positive attitude and evaluation of people to the implemented policy, which includes two aspects: psychological identification and cooperation and support in action. Therefore, the PI mentioned in this research refers to the attitude tendency of all interest groups related to employees to approve, affirm and support a series of policies and measures issued for this group.

\section{RESEARCH HYPOTHESIS, MODEL, AND DATA}

\subsection{Theoretical model}

On the basis of reviewing literature and related theories, a theoretical model is constructed. In the theoretical model, WM is used as independent variable, WE as dependent variable, and PI as moderating variable. In order to examine the impact of WM of Chinese skilled personnel on WE, the impact of PI on $\mathrm{WE}$, and the moderating role of PI on the impact of WM on WE. Figure 1 portrays the overall model.

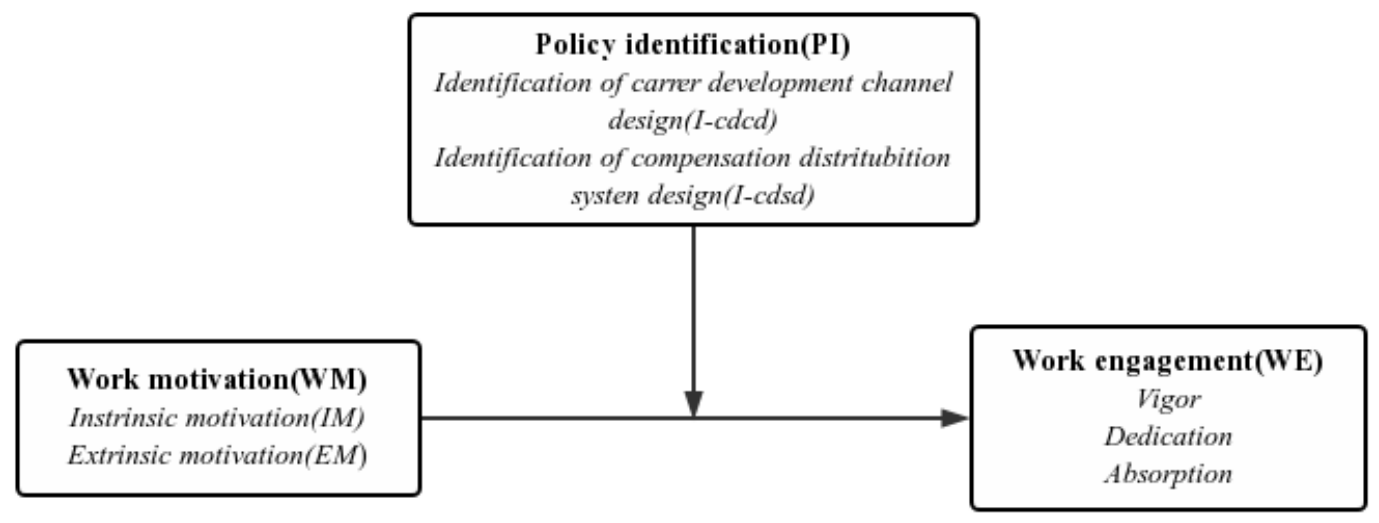

Figure 1. Proposed theoretical model

\section{2, Research hypothesis}

\subsubsection{Independent variable and dependent variable: work motivation and work engagement}

Based on many established motivation theories and studies, IM and EM are acknowledged as the fundamental tenets of motivation theory[2,3,4,5,10]. Employees may be driven by both IM and EM, motivating them to engage in work activities to fulfill different needs. Ultimately, the both elements would translate into the same outcome-increased engagement at work[11]. 
To the best of our knowledge, there is limited studies examined the association between WM and WE. Karatepe suggested that EM is the most reliable indicator of employee work engagement [18]. Salanova et al and Bakker \& Demerouti insisted that IM works more closely with WE, particularly related to absorption[13,14]. However, we cannot say what type of WM (intrinsic/extrinsic) would more tightly link to the vigor, the dedication, or the absorption of WE. Consequently, we hypothesize further the following:

\begin{tabular}{|l|}
\hline H 1: WM of Chinese skilled personnel positively associates $W E$ \\
\hline H la: IM of ... positively associates vigor \\
\hline H 1b: IM of ... positively associates dedication \\
\hline H lc: IM of ... positively associates absorption \\
\hline H 1d: EM of ... positively associates vigor \\
\hline H le: EM of ... positively associates dedication \\
\hline H 1f: EM of ... positively associates absorption \\
\hline
\end{tabular}

\subsubsection{Moderating variable and dependent} variable: policy identification and work engagement

PI refers to the positive attitude of the target group of the policy to the implemented policy, including psychological approval and support in action. On the basis of sorting out the relevant policies, 'Guidelines on
Salary Distribution of Skilled Personnel' is selected as the policy. The PI is divided into identification of career development channel design (I-cdcd) and identification of compensation distribution system design (I-cdsd) in this paper. Therefore, this paper considered the PI as a factor in improving WE of Chinese skilled personnel and proposed the following hypotheses:

\begin{tabular}{|c|}
\hline$H 2:$ PI of Chinese skilled personnel positively associates $W E$ \\
\hline$H 2 a: I-c d c d$ of ... positively associates vigor \\
\hline$H 2 b: I-c d c d$ of ... positively associates dedication \\
\hline$H 2 c: I-c d c d$ of ... positively associates absorption \\
\hline$H 2 d: I-c d s d$ of ... positively associates vigor \\
\hline$H 2 e: I-c d s d$ of ... positively associates dedication \\
\hline$H 2 f: I-c d s d$ of ... positively associates absorption \\
\hline
\end{tabular}

\subsubsection{The moderating role of policy identification}

PI of Chinese skilled personnel play a moderating role in the process of the influence of WM on WE. As such the following hypotheses were tested:

According to the above hypotheses, WM and PI positively associates WE. This paper supposes that the

\begin{tabular}{|c|}
\hline$H$ 3: PI of Chinese skilled personnel plays a moderating role in the effect of $W M$ on $W E$ \\
\hline$H 3 a: I-c d c d$ of ... plays a moderating role ... of IM on vigor \\
\hline$H 3 b: I-c d c d$ of $\ldots$ plays a moderating role ... of IM on dedication \\
\hline H 3c: I-cdcd of ... plays a moderating role ... of IM on absorption \\
\hline$H 3 d$ : I-cdcd of ... plays a moderating role ... of EM on vigor \\
\hline H 3e: I-cdcd of ... plays a moderating role ... of EM on dedication \\
\hline H 3f: I-cdcd of ... plays a moderating role ... of EM on absorption \\
\hline H 3g: I-cdsd of ... plays a moderating role ... of IM on vigor \\
\hline$H$ 3h: I-cdsd of ... plays a moderating role ... of IM on dedication \\
\hline H 3i: I-cdsd of ... plays a moderating role ... of IM on absorption \\
\hline H 3j: I-cdsd of ... plays a moderating role ... of EM on vigor \\
\hline$H 3 k$ : I-cdsd of ... plays a moderating role ... of EM on dedication \\
\hline H 3l: I-cdsd of ... plays a moderating role ... of EM on absorption \\
\hline
\end{tabular}

\subsection{Questionnaire design}

The questionnaire is designed into four parts.The first part is that respondent's basic information, mainly includes gender, domicile place, age, marital status, education background, working age, and Industry. The

\section{DATA ANALYSES}

\subsection{Data collection and processing}

Taking Chinese skilled personnel as sampling, 150 second part is scale of WM, which consists of IM and EM dimensions. Then third part is about WE, including vigor, dedication, absorption dimensions. Finally, the fourth part is scale of PI, including I-cded and I-cdsd. questionnaires were distributed totally, and 150 came back and all of them were valid to use as data in the research. The SPSS version 25 was used to analyse the obtained data. To enhance the understanding data, descriptive statistics was conducted. To determine the 
reliability of the variables used in the study, Cronbach's Alpha was conducted. To identify relationships on WM, WE and PI, Pearson's moment correlations were conducted. To determine the quantitative relationship of interdependence among the three variables, a linear regression model was used.

As illustrated in table 1 , the $\alpha$ coefficient of all variables and dimensions is above 0.8 , indicating that the reliability of the scales selected in this paper have good internal consistency
Table 1. Results of reliability

\begin{tabular}{ccc}
\hline Scales & Cronbach's $\alpha$ & Items \\
\hline WM & 0.885 & 12 \\
IM & 0.861 & 6 \\
EM & 0.813 & 6 \\
\hline WE & 0.945 & 9 \\
vigor & 0.908 & 3 \\
dedication & 0.885 & 3 \\
absorption & 0.881 & 3 \\
\hline PI & 0.947 & 8 \\
I-dccd & 0.918 & 4 \\
I-cdsd & 0.921 & 4 \\
\hline
\end{tabular}

In addition, the validity of the obtained data was tested in Table 2, which shows that all three scales were suitable for factor analysis.

Table 2. Results of validity

\begin{tabular}{cccc}
\hline Variables & KMO & Bartlett's & Sig. \\
\hline WM & 0.872 & 791.917 & 0.000 \\
WE & 0.897 & 1303.497 & 0.000 \\
PI & 0.913 & 1082.990 & 0.000
\end{tabular}

\subsection{Descriptive analysis}

\subsubsection{Descriptive analysis for the samples}

Table 3 shows the descriptive statistics for the samples. The proportion of male samples is slightly higher than that of female. Coincidentally, the number of skilled personnel with rural domicile is equal to the that of with urban domicile. In terms of age, 18-30 years old accounted for the largest proportion. As for marital status, the sample of unmarried skilled personnel is the largest. About educational background, the number of skilled personnel with an undergraduate education background is the largest. In terms of working age, the sample of people working for less than 2 years is the largest. With regard to industry, the financial industry and the education industry have the largest samples, while the transportation industry has the least, with only one sample.

Table 3. Respondents' demographic information

\begin{tabular}{|c|c|c|c|}
\hline Parameter & Category & $\mathrm{N}$ & $\%$ \\
\hline \multirow{2}{*}{ Gender } & Male & 83 & $55.33 \%$ \\
\hline & Female & 67 & $44.67 \%$ \\
\hline \multirow{2}{*}{ Domicile place } & Rural & 75 & $50 \%$ \\
\hline & Urban & 75 & $50 \%$ \\
\hline \multirow{3}{*}{ Age } & $18-30$ & 113 & $75.33 \%$ \\
\hline & $31-50$ & 32 & $21.33 \%$ \\
\hline & Older than 50 & 5 & $3.33 \%$ \\
\hline \multirow{3}{*}{ Marital status } & Single & 102 & $68 \%$ \\
\hline & Married & 46 & $30.67 \%$ \\
\hline & Others & 2 & $1.33 \%$ \\
\hline \multirow{4}{*}{ Educational status } & High school or below & 4 & $2.67 \%$ \\
\hline & Junior college & 26 & $17.33 \%$ \\
\hline & Undergraduate & 85 & $56.67 \%$ \\
\hline & Postgraduate or above & 35 & $23.33 \%$ \\
\hline \multirow{3}{*}{ Working age } & Less than 2 years & 73 & $48.67 \%$ \\
\hline & $2-5$ years & 33 & $22 \%$ \\
\hline & More than 5 years & 44 & $29.33 \%$ \\
\hline \multirow{7}{*}{ Industry } & Manufacturing & 8 & $5.33 \%$ \\
\hline & Construction & 11 & $7.33 \%$ \\
\hline & Transportation & 1 & $0.67 \%$ \\
\hline & Education & 23 & $15.33 \%$ \\
\hline & Finance & 25 & $16.67 \%$ \\
\hline & Real estate & 16 & $10.67 \%$ \\
\hline & Science and technology & 17 & $11.33 \%$ \\
\hline
\end{tabular}




\begin{tabular}{ccc} 
Medical & 17 & $11.33 \%$ \\
Commercial services & 15 & $10 \%$ \\
Others & 17 & $11.33 \%$ \\
\hline
\end{tabular}

\subsubsection{Descriptive analysis for the variables}

noteworthy is that the mean of IM (4.002) higher than the EM (3.856), and the mean of dedication (3.747) is higher than that of vigor and absorption.

Table 4 summarized descriptive statistics of the independent variable (WM), dependent variable (WE) and mediating variable (PI) in this paper. What is

Table 4. Descriptive statistics of the variables

\begin{tabular}{ccccccc}
\hline Variables & $\mathrm{N}=$ & Min & Max & Mean & Std. Dev & Median \\
\hline WM & 150 & 1.000 & 5.000 & 3.923 & 0.601 & 3.917 \\
IM & 150 & 1.000 & 5.000 & 4.002 & 0.655 & 4.000 \\
EM & 150 & 1.000 & 5.000 & 3.856 & 0.638 & 3.900 \\
\hline WE & 150 & 1.000 & 5.000 & 3.756 & 0.722 & 3.771 \\
vigor & 150 & 1.000 & 5.000 & 3.733 & 0.837 & 4.000 \\
dedication & 150 & 1.000 & 5.000 & 3.747 & 0.792 & 3.917 \\
absorption & 150 & 1.000 & 5.000 & 3.732 & 0.785 & 3.750 \\
\hline PI & 150 & 1.000 & 5.000 & 4.058 & 0.630 & 4.013 \\
I-cdcd & 150 & 1.000 & 5.000 & 4.042 & 0.684 & 4.000 \\
I-cdsd & 150 & 1.000 & 5.000 & 4.082 & 0.650 & 4.000 \\
\hline
\end{tabular}

\subsection{Correlation analysis}

\subsubsection{Correlation analysis of work motivation and work engagement}

From Table 5, the both of IM and EM have a

\begin{tabular}{|c|c|c|c|c|c|}
\hline & IM & EM & Vigor & Dedication & Absorption \\
\hline $\mathrm{IM}$ & 1 & & & & \\
\hline \multirow{2}{*}{$\mathrm{EM}$} & $0.727^{* \star}$ & 1 & & & \\
\hline & 0.000 & & & & \\
\hline \multirow{2}{*}{ Vigor } & $0.639^{\star \star}$ & $0.550^{\star *}$ & 1 & & \\
\hline & 0.000 & 0.000 & & & \\
\hline \multirow{2}{*}{ Dedication } & $0.616^{* *}$ & $0.499^{* *}$ & $0.901^{* *}$ & 1 & \\
\hline & 0.000 & 0.000 & 0.000 & & \\
\hline \multirow{2}{*}{ Absorption } & $0.618^{* \star}$ & $0.468^{* *}$ & $0.771^{* *}$ & $0.879^{* *}$ & 1 \\
\hline & 0.000 & 0.000 & 0.000 & 0.000 & \\
\hline
\end{tabular}

\subsubsection{Correlation analysis of work motivation and policy engagement}

According to Table 6, there is a significant positive correlation between IM, EM and I-cdcd, and the significant positive correlation with all dimensions of WE, and the correlation coefficients rang from 0.46 to 0.64 . And the correlation coefficients between IM and dimensions of WE is higher than that between EM and dimensions of WE.

Table 5. Correlation matrix of work motivation and work engagement

Table 6. Correlation matrix of work motivation and policy identification

\begin{tabular}{ccccc}
\hline & IM & EM & I-cdcd & l-cdsd \\
\hline IM & 1 & & & \\
\hline \multirow{2}{*}{ EM } & $0.727^{* *}$ & 1 & 1 \\
\hline \multirow{2}{*}{ I-cdcd } & 0.000 & $0.659^{* *}$ & $0.655^{* *}$ & \\
& 0.000 & 0.000 & & \\
\hline
\end{tabular}




\begin{tabular}{|c|c|c|c|c|}
\hline \multirow{2}{*}{ I-cdsd } & $0.662^{* *}$ & 0.664 & 0.899 & 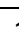 \\
\hline & & & & \\
\hline
\end{tabular}

\subsubsection{Correlation analysis of policy identification and work engagement}

Table 7 shows a significant positive correlation between dimensions of PI and WE, and the correlation coefficient between I-cdcd and WE is slightly higher than that between I-cdsd and WE.

Table 7. Correlation matrix of policy identification and work engagement

\begin{tabular}{|c|c|c|c|c|c|}
\hline & I-cdcd & I-cdsd & Vigor & Dedication & Absorption \\
\hline I-cdcd & 1 & & & & \\
\hline \multirow{2}{*}{ I-cdsd } & $0.899 * \star$ & 1 & & & \\
\hline & 0.000 & & & & \\
\hline \multirow{2}{*}{ Vigor } & $0.493^{* *}$ & $0.476^{\star \star}$ & 1 & & \\
\hline & 0.000 & 0.000 & & & \\
\hline \multirow{2}{*}{ Dedication } & $0.539 * *$ & $0.518^{\star \star}$ & $0.901^{\star \star}$ & 1 & \\
\hline & 0.000 & 0.000 & 0.000 & & \\
\hline \multirow{2}{*}{ Absorption } & $0.542^{\star \star *}$ & $0.515^{\star \star}$ & $0.771^{\star \star}$ & $0.879 * \star$ & 1 \\
\hline & 0.000 & 0.000 & 0.000 & 0.000 & \\
\hline
\end{tabular}

$* \mathrm{p}<0.05 * * \mathrm{p}<0.01$

\subsection{Regression analysis}

\subsection{1 work motivation and work engagement}

Table 8. Regression results of work motivation and work engagement

\begin{tabular}{|c|c|c|c|c|c|c|c|c|}
\hline & \multicolumn{2}{|c|}{ Unstd. Coefficients } & \multirow{2}{*}{$\frac{\text { Std. Coefficients }}{\text { Beta }}$} & \multirow{2}{*}{$\mathrm{t}$} & \multirow{2}{*}{$\mathrm{p}$} & \multirow{2}{*}{ VIF } & \multirow{2}{*}{$\mathrm{R}^{2}$} & \multirow{2}{*}{$\mathrm{F}$} \\
\hline & B & Std. Error & & & & & & \\
\hline \multicolumn{9}{|l|}{ Vigor } \\
\hline Constant & 0.320 & 0.322 & - & 0.993 & 0.322 & - & \multirow{3}{*}{0.449} & $F(2,147)=59.7$ \\
\hline EM & 0.215 & 0.111 & 0.173 & 1.936 & 0.055 & 2.119 & & 87 \\
\hline IM & 0.648 & 0.108 & 0.534 & 5.987 & $0.000^{\star \star}$ & 2.119 & & $p=0.000$ \\
\hline \multicolumn{9}{|l|}{ Dedication } \\
\hline Constant & 0.655 & 0.338 & - & 1.940 & 0.054 & - & \multirow{3}{*}{0.384} & \multirow{3}{*}{$\begin{array}{c}F(2,147)=45.7 \\
36 p=0.000\end{array}$} \\
\hline EM & 0.128 & 0.116 & 0.104 & 1.099 & 0.274 & 2.119 & & \\
\hline IM & 0.650 & 0.113 & 0.540 & 5.728 & $0.000^{\star *}$ & 2.119 & & \\
\hline \multicolumn{9}{|l|}{ Absorption } \\
\hline Constant & 0.724 & 0.337 & - & 2.149 & $0.033^{*}$ & - & \multirow{3}{*}{0.381} & \multirow{3}{*}{$\begin{array}{c}F(2,147)=45.3 \\
32 p=0.000\end{array}$} \\
\hline EM & 0.047 & 0.116 & 0.038 & 0.404 & 0.687 & 2.119 & & \\
\hline $\mathrm{IM}$ & 0.706 & 0.113 & 0.589 & 6.242 & $0.000 * \star$ & 2.119 & & \\
\hline
\end{tabular}
$* \mathrm{p}<0.05 * * \mathrm{p}<0.01$

The effects of EM and IM on all three dimensions of WE were tested in Table 8. EM and IM were taken as independent variables marked $\mathrm{X} 1$ and $\mathrm{X} 2$ respectively, and vigor as dependent variable marked $\mathrm{Y} 1$, the model formula is: $\mathrm{Y} 1=0.320+0.215^{*} \mathrm{X} 1+0.648 * \mathrm{X} 2$. The $\mathrm{R} 2$ of the model is 0.449 , indicating that the WM can explain the $44.9 \%$ changes of vigor. VIF less than 5 indicating that there is no multicollinearity problem. It can be concluded from the table EM had no effect on vigor $(t=1.936, P=0.055>0.05)$, while $I M$ had a significant positive influence on vigor $(\mathrm{t}=5.987, \mathrm{P}$
$=0.000<0.01)$.

When dedication is taken as dependent variable marked Y2, the model formula is: $\mathrm{Y} 2=0.655+$ $0.128 * \mathrm{X} 1+0.650 * \mathrm{X} 2$. The $\mathrm{R} 2$ value is 0.384 , which means that WM can explain the $38.4 \%$ changes of dedication. All VIF values are less than 5, which means there is no multicollinearity problem. And the table draws that EM had no effect on dedication( $t=1.099$, $\mathrm{p}=0.274>0.05)$, while IM had a significant positive influence on dedication $(\mathrm{t}=5.728, \mathrm{p}=0.000<0.01)$. 
When using absorption as the dependent variable marked Y3, the model formula is: $\mathrm{Y} 3=0.724+$ $0.047 * \mathrm{X} 1+0.706 * \mathrm{X} 2$. The model $\mathrm{R} 2$ is 0.381 , which means that WM can explain the $38.1 \%$ change of absorption. In addition, there is no multicollinearity problem $(\mathrm{VIF}=0.381)$. And Table 8 displays that $\mathrm{EM}$ had no effect on dedication $(\mathrm{t}=0.404, \mathrm{p}=0.687>0.05)$, while IM had a significant positive influence on $\operatorname{absorption}(\mathrm{t}=6.242, \mathrm{p}=0.000<0.01)$.

\subsubsection{Policy identification and work engagement}

Table 9. Regression results of policy identification and work engagement

\begin{tabular}{|c|c|c|c|c|c|c|c|c|}
\hline & \multicolumn{2}{|c|}{ Unstd. Coefficients } & \multirow{2}{*}{$\frac{\text { Std. Coefficients }}{\text { Beta }}$} & \multirow{2}{*}{$\mathrm{t}$} & \multirow{2}{*}{$p$} & \multirow{2}{*}{ VIF } & \multirow{2}{*}{$\mathrm{R}^{2}$} & \multirow{2}{*}{$\mathrm{F}$} \\
\hline & B & Std. Error & & & & & & \\
\hline \multicolumn{9}{|l|}{ Vigor } \\
\hline Constant & 1.142 & 0.354 & - & 3.223 & $0.002^{* \star}$ & - & & $F(2,147)=28$ \\
\hline I-cdcd & 0.495 & 0.170 & 0.421 & 2.909 & $0.004^{\star *}$ & 4.270 & 0.281 & 675 \\
\hline I-cdsd & 0.145 & 0.173 & 0.121 & 0.838 & 0.404 & 4.270 & & $p=0.000$ \\
\hline \multicolumn{9}{|l|}{ Dedication } \\
\hline Constant & 1.104 & 0.347 & - & 3.180 & $0.002^{\star \star}$ & - & & $F(2,147)=31.0$ \\
\hline I-cdcd & 0.521 & 0.167 & 0.446 & 3.122 & $0.002^{* \star}$ & 4.270 & 0.297 & 54 \\
\hline I-cdsd & 0.131 & 0.170 & 0.110 & 0.770 & 0.443 & 4.270 & & $p=0.000$ \\
\hline \multicolumn{9}{|l|}{ Absorption } \\
\hline Constant & 1.132 & 0.347 & - & 3.263 & $0.001^{\star \star}$ & - & & $F(2,147)=30$. \\
\hline I-cdcd & 0.545 & 0.167 & 0.468 & 3.266 & $0.001^{\star \star}$ & 4.270 & 0.293 & 421 \\
\hline I-cdsd & 0.097 & 0.170 & 0.082 & 0.569 & 0.570 & 4.270 & & $p=0.000$ \\
\hline
\end{tabular}

$* \mathrm{p}<0.05 * * \mathrm{p}<0.01$

The impacts of I-cdcd and I-cdsd on all three dimensions of WE were tested in Table 9. I-cdcd and I-cdsd were taken as independent variables marked X3 and $\mathrm{X} 4$ respectively, and vigor as dependent variable marked Y1. The model formula is: $Y 1=1.142+$ $0.495 * \mathrm{X} 3+0.145^{*} \mathrm{X} 4$. The $\mathrm{R} 2$ of the model is 0.281 , indicating that the PI can explain the $28.1 \%$ changes of vigor. VIF less than 5 indicating that there is no multicollinearity problem. Figures show that I-cdcd had no effect on vigor $(t=2.909, p=0.004<0.01)$, while I-cdsd had a significant positive influence on vigor $(\mathrm{t}=0.838$, $\mathrm{p}=0.404>0.05$ ).

When dedication is taken as dependent variable marked $\mathrm{Y} 2$, the model formula is: $\mathrm{Y} 2=1.104+$ $0.521 * \mathrm{X} 3+0.131 * \mathrm{X} 4$. The $\mathrm{R} 2$ value is 0.297 , which means that PI can explain $29.7 \%$ of the changes in dedication. In addition, all VIF values are less than 5 , which means there is no multicollinearity problem. Table 9 shows that I-cdsd had no effect on dedication $(\mathrm{t}=0.770, \mathrm{p}=0.443>0.05)$, while I-cdscd had a significant positive influence on dedication $(\mathrm{t}=3.122$, $\mathrm{p}=0.002<0.01)$.

When using absorption as the dependent variable marked Y3, the model formula is: $\mathrm{Y} 3=1.132+$
$0.545 * \mathrm{X} 3+0.097 * \mathrm{X} 4$. The model $\mathrm{R} 2$ is 0.293 , which means that PI can explain the $29.3 \%$ change of absorption. And there is no multicollinearity problem $(\mathrm{VIF}=0.293)$. The regression coefficient of I-cdcd was $0.545(\mathrm{t}=3.266, \mathrm{p}=0.001<0.01$, indicating that I-cdcd had no effect on dedication. The regression coefficient of I-cdsd was $0.097(\mathrm{t}=0.569$, $\mathrm{p}=0.570>0.05)$, indicating that I-cdsd had a significant positive influence on absorption.

\subsubsection{Mediation tests of policy identification}

\subsubsection{The moderating role of policy identification on the impact of intrinsic motivation on vigor}

As shown in Table 10, the independent variable (IM) has a significant influence on vigor $(\mathrm{t}=11.367$, $\mathrm{p}=0.000<0.05)$ without considering the interference of the moderating variables in model 1 . While in model 2 and model 3, the interaction terms of IM*I-cdcd $(\mathrm{t}=-0.044, \mathrm{P}=0.965>0.05)$ and $\mathrm{IM} * \mathrm{I}-\mathrm{cdsd} \quad(\mathrm{t}=-0.328$, $\mathrm{p}=0.743>0.05)$ did not show significant, which means that when IM affects vigor, the magnitude of the influence remains the same when the moderating variables(PI) are at different levels. 
Table 10. The moderating role of PI on the impact of IM on vigor

\begin{tabular}{|c|c|c|c|c|c|c|c|c|c|}
\hline \multirow{3}{*}{ Variable } & \multicolumn{9}{|c|}{ Vigor } \\
\hline & \multicolumn{3}{|c|}{ Model 1} & \multicolumn{3}{|c|}{ Model 2} & \multicolumn{3}{|c|}{ Model 3} \\
\hline & B & $\mathrm{t}$ & $p$ & B & $\mathrm{t}$ & $p$ & B & $\mathrm{t}$ & $p$ \\
\hline Constant & 3.758 & 86.304 & $0.000 * *$ & 3.758 & 87.401 & $0.000 * *$ & 3.762 & 84.624 & $0.000 * *$ \\
\hline $\mathrm{IM}$ & 0.737 & 11.367 & $0.000^{* *}$ & 0.482 & 5.748 & $0.000 * *$ & 0.574 & 6.762 & $0.000^{* *}$ \\
\hline$\left|M^{*}\right|-c d c d$ & & & & -0.002 & -0.044 & 0.965 & & & \\
\hline$\left|M^{*}\right|-c d s d$ & & & & & & & -0.015 & -0.328 & 0.743 \\
\hline $\mathrm{R}^{2}$ & \multicolumn{3}{|c|}{0.466} & \multicolumn{3}{|c|}{0.533} & \multicolumn{3}{|c|}{0.495} \\
\hline$\triangle R^{2}$ & \multicolumn{3}{|c|}{0.466} & \multicolumn{3}{|c|}{0.000} & \multicolumn{3}{|c|}{0.000} \\
\hline$F$ & \multicolumn{3}{|c|}{$F(1,148)=129 \cdot 207, p=0.000$} & \multicolumn{3}{|c|}{$F(3,146)=55.488, p=0.000$} & \multicolumn{3}{|c|}{$F(3,146)=47.773, p=0.000$} \\
\hline
\end{tabular}

$* \mathrm{p}<0.05 * * \mathrm{p}<0.01$

\subsubsection{The moderating role of policy identification} on the impact of intrinsic motivation on dedication

According to Table 11, IM had a significant positive effect on dedication $(\mathrm{t}=8.582, \mathrm{p}=0.000<0.05)$. When adding IM*I-cded and IM*I-cdsd into model 2 and model 3 respectively for regression analysis on dedication, the interaction terms of IM*I-cded $(\mathrm{t}=-0.083, \mathrm{p}=0.934>0.05)$ and $\mathrm{IM} * \mathrm{I}-\mathrm{cdsd}(\mathrm{t}=-0.129$, $\mathrm{p}=0.897>0.05)$ did not show significant, which means that when IM affects dedication, the magnitude of the influence remains the same when the moderating variables(PI) are at different levels.

Table 11. The moderating role of PI on the impact of IM on dedication

\begin{tabular}{|c|c|c|c|c|c|c|c|c|c|}
\hline \multirow{3}{*}{ Variable } & \multicolumn{9}{|c|}{ Dedication } \\
\hline & \multicolumn{3}{|c|}{ Model 1} & \multicolumn{3}{|c|}{ Model 2} & \multicolumn{3}{|c|}{ Model 3} \\
\hline & $B$ & $\mathrm{t}$ & $p$ & $B$ & $\mathrm{t}$ & $p$ & $B$ & $\mathrm{t}$ & $p$ \\
\hline Constant & 3.751 & 68.921 & $0.000^{* \star}$ & 3.752 & 72.741 & $0.000^{* *}$ & 3.753 & 67.978 & $0.000^{* *}$ \\
\hline $\mathrm{IM}$ & 0.696 & 8.582 & $0.000^{\star *}$ & 0.298 & 2.961 & $0.004^{\star *}$ & 0.473 & 4.483 & $0.000^{* *}$ \\
\hline$\left|\mathrm{M}^{\star}\right|-c d c d$ & & & & -0.004 & -0.083 & 0.934 & & & \\
\hline$\left|\mathrm{M}^{*}\right|-c d s d$ & & & & & & & -0.007 & -0.129 & 0.897 \\
\hline$R^{2}$ & \multicolumn{3}{|c|}{0.332} & \multicolumn{3}{|c|}{0.462} & \multicolumn{3}{|c|}{0.377} \\
\hline$\Delta R^{2}$ & \multicolumn{3}{|c|}{0.332} & \multicolumn{3}{|c|}{0.000} & \multicolumn{3}{|c|}{0.000} \\
\hline $\mathrm{F} \cdot$ & \multicolumn{3}{|c|}{$F(1,148)=73.649, p=0.000$} & \multicolumn{3}{|c|}{$F(3,146)=41.753, p=0.000$} & \multicolumn{3}{|c|}{$F(3,146)=29.445, p=0.000$} \\
\hline
\end{tabular}

4.4.3.3 The moderating role of policy identification on the impact of intrinsic motivation on absorption

Attested by Table 12, the independent variable (IM) has a significant influence on absorption $(\mathrm{t}=9.302, \mathrm{p}=0.000<0.05)$ without considering the interference of the moderating variables. While in model 2 and model 3 , the interaction items of IM*I-cdcd $(\mathrm{t}=-0.044, \quad \mathrm{P}=0.965>0.05)$ and $\mathrm{IM}^{*} \mathrm{I}-\mathrm{cdsd}(\mathrm{t}=-0.159$, $\mathrm{p}=0.874>0.05)$ did not not show significant. When IM affects absorption, therefore, the magnitude of the influence remains the same when the moderating variables(PI) are at different levels.

Table 12.The moderating role of PI on the impact of IM on absorption

\begin{tabular}{|c|c|c|c|c|c|c|c|c|c|}
\hline \multirow{3}{*}{ Variable } & \multicolumn{9}{|c|}{ Absorption } \\
\hline & \multicolumn{3}{|c|}{ Model 1} & \multicolumn{3}{|c|}{ Model 2} & \multicolumn{3}{|c|}{ Model 3} \\
\hline & $B$ & $\mathrm{t}$ & $p$ & $B$ & $\mathrm{t}$ & $p$ & B & $\mathrm{t}$ & $p$ \\
\hline Constant & 3.733 & 72.663 & $0.000^{\star \star}$ & 3.730 & 78.389 & $0.000^{* *}$ & 3.735 & 71.457 & $0.000^{* *}$ \\
\hline $\mathrm{IM}$ & 0.712 & 9.302 & $0.000^{* *}$ & 0.307 & 3.309 & $0.001^{* *}$ & 0.510 & 5.110 & $0.000^{* *}$ \\
\hline$\left|M^{*}\right|-c d c d$ & & & & 0.009 & 0.184 & 0.854 & & & \\
\hline$\left|\mathrm{M}^{*}\right|-c d s d$ & & & & & & & -0.008 & -0.159 & 0.874 \\
\hline$R^{2}$ & & 0.369 & & & 0.514 & & & 0.408 & \\
\hline
\end{tabular}




\section{$\triangle R^{2}$ \\ $\mathrm{F}$. \\ $* \mathrm{p}<0.05 * * \mathrm{p}<0.01$ \\ 4.4.3.4 The moderating role of policy identification on the impact of extrinsic motivation on vigor}

Table 13 shows that EM had a significant positive effect on vigor $(\mathrm{t}=10.933, \mathrm{p}=0.000<0.05)$ in model 1 .
0.000

0.000

$F(3,146)=51.501, p=0.000$
$F(3,146)=33.480, p=0.000$

While in model 2 and model 3 , the interaction terms of EM*I-cdcd $(\mathrm{t}=0.237, \mathrm{p}=0.813>0.05)$ and $\mathrm{EM} * \mathrm{I}$-cdsd $(\mathrm{t}=-0.564, \mathrm{p}=0.574>0.05)$ did not show significant, which means that when EM affects vigor, the magnitude of the influence remains the same when the moderating variables(PI) is at different levels.

Table 13. The moderating role of PI on the impact of EM on vigor

\begin{tabular}{|c|c|c|c|c|c|c|c|c|c|}
\hline \multirow{3}{*}{ Variable } & \multicolumn{9}{|c|}{ Vigor } \\
\hline & \multicolumn{3}{|c|}{ Model 1} & \multicolumn{3}{|c|}{ Model 2} & \multicolumn{3}{|c|}{ Model 3} \\
\hline & B & $\mathrm{t}$ & $p$ & B & $\mathrm{t}$ & $p$ & B & $\mathrm{t}$ & $p$ \\
\hline Constant & 3.758 & 84.783 & $0.000^{* *}$ & 3.755 & 88.357 & $0.000 * \star$ & 3.765 & 83.926 & $0.000^{* *}$ \\
\hline EM & 0.726 & 10.933 & $0.000^{* \star}$ & 0.472 & 6.011 & $0.000^{\star \star}$ & 0.543 & 6.452 & $0.000^{* *}$ \\
\hline EM*l-cdcd & & & & 0.011 & 0.237 & 0.813 & & & \\
\hline EM*l-cdsd & & & & & & & -0.027 & -0.564 & 0.574 \\
\hline $\mathrm{R}^{2}$ & \multicolumn{3}{|c|}{0.447} & \multicolumn{3}{|c|}{0.540} & \multicolumn{3}{|c|}{0.487} \\
\hline$\triangle R^{2}$ & \multicolumn{3}{|c|}{0.447} & \multicolumn{3}{|c|}{0.000} & \multicolumn{3}{|c|}{0.001} \\
\hline $\mathrm{F} \cdot$ & \multicolumn{3}{|c|}{$F(1,148)=119.524, p=0.000$} & \multicolumn{3}{|c|}{$F(3,146)=57.049, p=0.000$} & \multicolumn{3}{|c|}{$F(3,146)=46.169, p=0.000$} \\
\hline
\end{tabular}

\subsubsection{The moderating role of policy identification} on the impact of extrinsic motivation on dedication

In Table 14, EM had a significant positive effect on dedication $(\mathrm{t}=5.554, \mathrm{p}=0.000<0.05)$ in model 1 . While in model 2 and model 3 , the interaction terms of EM*I-cdcd $(\mathrm{t}=0.053, \mathrm{p}=0.958>0.05)$ and $\mathrm{EM} * \mathrm{I}-\mathrm{cdsd}$ $(\mathrm{t}=-0.539, \mathrm{p}=0.591>0.05)$ did not show significant, which means that when EM affects dedication, the magnitude of the influence remains the same when the moderating variables(PI) is at different levels.

Table 14. The moderating role of PI on the impact of EM on dedication

\begin{tabular}{|c|c|c|c|c|c|c|c|c|c|}
\hline \multirow{3}{*}{ Variable } & \multicolumn{9}{|c|}{ Dedication } \\
\hline & \multicolumn{3}{|c|}{ Model 1} & \multicolumn{3}{|c|}{ Model 2} & \multicolumn{3}{|c|}{ Model 3} \\
\hline & B & t & $\mathrm{p}$ & B & $\mathrm{t}$ & $p$ & B & $\mathrm{t}$ & $p$ \\
\hline Constant & 3.751 & 61.910 & $0.000^{* *}$ & 3.750 & 70.860 & $0.000 * \star$ & 3.760 & 64.182 & $0.000^{* \star}$ \\
\hline EM & 0.504 & 5.554 & $0.000^{* *}$ & 0.027 & 0.273 & 0.785 & 0.143 & 1.303 & 0.194 \\
\hline EM*l-cdcd & & & & 0.003 & 0.053 & 0.958 & & & \\
\hline EM*l-cdsd & & & & & & & -0.033 & -0.539 & 0.591 \\
\hline $\mathrm{R}^{2}$ & \multicolumn{3}{|c|}{0.172} & \multicolumn{3}{|c|}{0.428} & \multicolumn{3}{|c|}{0.299} \\
\hline$\triangle R^{2}$ & \multicolumn{3}{|c|}{0.172} & \multicolumn{3}{|c|}{0.000} & \multicolumn{3}{|c|}{0.001} \\
\hline $\mathrm{F} \cdot$ & \multicolumn{3}{|c|}{$F(1,148)=30.850, p=0.000$} & \multicolumn{3}{|c|}{$F(3,146)=36.486, p=0.000$} & \multicolumn{3}{|c|}{$F(3,146)=20.805, p=0.000$} \\
\hline
\end{tabular}

$* \mathrm{p}<0.05 * * \mathrm{p}<0.01$

\subsubsection{The moderating role of policy identification} on the impact of extrinsic motivation on absorption

As stated in Table 15, EM had a significant positive effect on absorption $(\mathrm{t}=5.472, \mathrm{p}=0.000<0.05)$ in model
1. While in model 2 and model 3, the interaction terms of EM*I-cded $(\mathrm{t}=-0.005, \mathrm{p}=0.996>0.05)$ and $\mathrm{EM} * \mathrm{I}-\mathrm{cdsd}$ $(\mathrm{t}=-0.537, \mathrm{p}=0.592>0.05)$ did not show significant, which means that when EM affects absorption, the magnitude of the influence remains the same when the moderating variables(PI) is at different levels.

Table 15.The moderating role of PI on the impact of EM on absorption

\begin{tabular}{|c|c|c|c|c|c|c|c|c|c|}
\hline \multirow{3}{*}{ Variable } & \multicolumn{9}{|c|}{ Absorption } \\
\hline & \multicolumn{3}{|c|}{ Model 1} & \multicolumn{3}{|c|}{ Model 2} & \multicolumn{3}{|c|}{ Model 3} \\
\hline & B & $\mathrm{t}$ & $p$ & B & $\mathrm{t}$ & $\mathrm{p}$ & B & $\mathrm{t}$ & $p$ \\
\hline Constant & 3.733 & 63.294 & $0.000 * \star$ & 3.733 & 75.980 & $0.000^{* *}$ & 3.741 & 66.118 & $0.000^{* \star}$ \\
\hline
\end{tabular}




\begin{tabular}{|c|c|c|c|c|c|c|c|c|c|}
\hline EM & 0.484 & 5.472 & $0.000^{\star \star}$ & -0.027 & -0.298 & 0.766 & 0.118 & 1.112 & 0.268 \\
\hline $\mathrm{EM}^{\star} \mid-\mathrm{cdcd}$ & & & & -0.000 & -0.005 & 0.996 & & & \\
\hline EM*I-cdsd & & & & & & & -0.032 & -0.537 & 0.592 \\
\hline $\mathrm{R}^{2}$ & \multicolumn{3}{|c|}{0.168} & \multicolumn{3}{|c|}{0.478} & \multicolumn{3}{|c|}{0.307} \\
\hline$\triangle R^{2}$ & \multicolumn{3}{|c|}{0.168} & \multicolumn{3}{|c|}{0.000} & \multicolumn{3}{|c|}{0.001} \\
\hline $\mathrm{F}$ & \multicolumn{3}{|c|}{$F(1,148)=29.947, p=0.000$} & \multicolumn{3}{|c|}{$F(3,146)=44.486, p=0.000$} & \multicolumn{3}{|c|}{$F(3,146)=21.527, p=0.000$} \\
\hline
\end{tabular}

\section{CONCLUSION}

This paper developed and tested a research model that investigated the relationship among WM, WE and PI. This paper taken Chinese skilled personnel as the sample to carry out the questionnaire survey to obtain the primary data. Based on the collected data, descriptive analysis, correlation analysis and regression analysis were conducted, and the following conclusions were finally obtained: (1)WM and WE are positively correlated. In detail, IM had significant impacts on all three dimensions of WE of skilled personnel. Therefore, Hypotheses 1, 1a, 1b, 1c were supported; (2)A significant relationship between PI and WE is proved, I-cdcd positively associates all three dimensions of WE, thus providing support for Hypotheses 2, 2a, 2b, and 2c; (3) However, the results of this study showed no indication that PI plays a moderating role in the process of WM impacts on WE.

Based on the findings, this paper proposes following recommendations. It is crucial for management to stimulate Chinese skilled personnel internal motivations, such as the satisfaction of work interest, and the sense of competence, so that skilled personnel can be more engaged in work. In addition, supplementing the means to stimulate EM, such as salary and benefits. The two-pronged approach further stimulates WE of Chinese skilled personnel. For another, it is important for organizations to have an in-depth understanding of their skilled personnel identification of relevant policies, and to strengthen the propaganda within the organization to enable employees have a sophisticated understanding of relevant policies, thereby enhancing employees' PI and increasing their WE.

The contributions made here have wide applicability. Firstly, although the impact of WM on WE has largely examined, the impact processes underlying the mediating role of PI remained largely unexplored. In this regard, this paper therefore might contribute to the extending and linking of two separate literature (WM and WE, and PI). Secondly, the majority of previous studies related to WM and WE with limited academic attention focused on the skilled personnel. Due to the traits of skilled personnel as unique human resource, the impact process of WM of skilled personnel on WE plays an essential role to improve organizational performance. Hence, focusing on skilled personnel are innovative and can yield important insights into complex managerial problems. Despite the contributions of this study, there are several noteworthy limitations. (1) Most of the questionnaires came from several industries, failing to balance the number of samples in different industries. And only 150 questionnaire were collected, so the sample size is not enough large. (2) Research has shown that WM, especially IM, is subject to internal changes over time [15]. We cannot rule out the potential interrelationships between WM and WE. Future research should therefore adopt a longitudinal designs to examine the trajectory of changes in WE and and provide more reliable evidence for the hypothetical causal effects.

\section{REFERENCES}

[1] Pinder, C. C. (1998). Work motivation in organizational behavior. $\mathrm{Nj}$ Prentice Hall.

[2] Amabile et al. (1994). The work preference inventory: assessing intrinsic and extrinsic motivational orientations. Journal of Personality \& Social Psychology.

[3] Deci, E. L. (2004). Intrinsic motivation and self-determination in human behavior. Encyclopedia of Applied Psychology, 3(2), 437-448.

[4] Hackman, J. (1976). Motivation through the design of work: test of a theory. Organizational Behavior \& Human Performance, 16(2), 250-279.

[5] Ryan, R. M., \& Deci, E. L. (2000). Intrinsic and extrinsic motivations: classic definitions and new directions. Contemp Educ Psychol, 25, 54-67.

[6] Schaufeli, W.B., et al. (2002). Burnout and engagement in university students: a cross-national study. Journal of Cross-Cultural Psychology, 33(5), 464-481.

[7] Bakker, A.B., Demerouti, E. (2007) 'The Job Demands-Resources Model: State of the Art' Journal of Managerial Psychology. 22 (3), 309-328.

[8] Schaufeli, W. B., \& Bakker, A. B. (2003). UWESUtrecht Work Engagement Scale: Test manual (Unpublished manuscript). Department of Psychology, Utrecht University, Utrecht, The Netherlands. 
[9] Sang, L.C., \& Liu, B.M. (1991). Viewing the mass foundation of Shanghai housing reform from policy identification. Politics and Law. 3, 17.

[10] Sansone, C., \& Harackiewicz, J. M. (2012). Intrinsic and extrinsic motivation: the search for optimal motivation and performance. contemporary psychology apa review of books.

[11] Shkoler, O., \& Kimura, T. (2020). How does work motivation impact employees' investment at work and their job engagement? a moderated-moderation perspective through an international lens. Frontiers in Psychology, 11.

[12] Karatepe, O. M. (2013). High-performance work practices and hotel employee performance: the mediation of work engagement. International Journal of Hospitality Management, 32(1), 132-140.

[13] Bakker, A. B., \& Demerouti, E. (2008). Towards a model of work engagement. Career Development International, 13(3), 209-223.

[14] Salanova, M., Agut, S., \& JM Peiró. (2005). Linking organizational resources and work engagement to employee performance and customer loyalty: the mediation of service climate. Journal of Applied Psychology, 90(6), 1217-1227.

[15] Vandercammen, L., Hofmans, J. , \& Theuns, P. . (2014). The mediating role of affect in the relationship between need satisfaction and autonomous motivation. Journal of Occupational \& Organizational Psychology, 87(1), 62-79. 